\title{
Consideraciones pedagógicas para el reconocimiento de la identidad personal y colectiva de las personas sordas
}

\author{
Pedagogical considerations for recognition \\ of personal and collective identity of the deaf \\ people
}

\section{Palabras clave}

Personas sordas, evaluación, participación, identidad, empoderamiento, inclusión.

\section{Keywords}

Deaf people, evaluation, participation, identity, empowering, inclusion.
El pensamiento, la reflexión y la comunicación materializan la esencia de la humanidad. Todas las construcciones humanas a lo largo de la historia parten de la libertad de acción y desarrollo en estos tres ámbitos. Según lo expuesto por Freire (2005), al sacrificar la palabra de su dimensión activa, se sacrifica también, automáticamente, la reflexión, transformándose en palabrerío, que termina siendo mero verbalismo. El propósito de la educación, o proceso de adquisición de aprendizajes, es la práctica de libertad de pensamiento, reflexión y acción. Sin la debida dialogicidad, tal práctica se torna lineal, regresando a las concepciones obsoletas del estudiante como 'depositario'. La bilateralidad en la dialogicidad coloca al estudiante como co-actor del proceso, siendo su voz partícipe en la transformación de constructos y cambios de paradigmas.

El poder transformador que posee la voz de los alumnos en la educación, como lo exponen Rudduck y Flutter (2007), implica un cambio esencial de percepción y de práctica en el contexto, y parte de esta trasformación se puede lograr mediante una relación participativa y colaborativa entre docentes y estudiantes en el proceso de evaluación. La escuela es el contexto que reproduce aspectos sociales en

\section{Yinzú Nairouz}

‘yinzun@gmail.com〉

Doctoranda en Educación. Universidad Autónoma de Barcelona

\section{Alexandra Cedeño Boada ‘alexandraccbı@gmail.com» \\ Docente en la U.E.E.B "Ofelia \\ Tancredi de Corredor" (Mérida- Venezuela). Intérprete de Lengua de Señas Venezolana}

\author{
Para citar: \\ Nairouz, Y. y Cedeño, A. (20I4): \\ "Consideraciones pedagógicas para \\ el reconocimiento de la identidad \\ personal y colectiva de las personas \\ sordas”, Revista Española de \\ Discapacidad, 2 (2): 255-260. \\ $<$ http://dx.doi.org/IO.5569/2340- \\ 5 I04.02.02.I $5>$
}


un ambiente idóneo para la práctica; de los aprendizajes que en ella se generen dependerá el tipo de participación que los individuos tendrán al intervenir en los ámbitos sociales regulares. Una participación activa en los procesos de evaluación genera un pensamiento crítico y transformador de la realidad educativa, lo cual repercute en las habilidades de percepción y transformación social.

En este sentido, teniendo en cuenta lo expuesto, se pueden generar cambios en la realidad educativa de las personas sordas en la medida que se aumente su participación y se preste atención a su voz, en especial en la evaluación, por ser el principal evento enjuiciador de la escuela. Es decir, si se reconoce el protagonismo de las personas sordas en su evaluación educativa, mediante la transformación de percepciones y prácticas inclusivas en la escuela, entonces la emancipación y el empoderamiento se reflejarán en la identidad de cada sujeto, y por ende en la comunidad sorda en general. Esto conduce a cuestionar qué es lo tradicionalmente aceptado y los efectos en los procesos educativos y, más allá, cuál es el verdadero compromiso a realizar para lograr la transformación deseada en la educación de las personas sordas como un aspecto determinante en la formación y el reconocimiento de su identidad.

La identidad de las personas sordas se presenta de diversas formas: cultural, lingüística y colectivamente; y todas ellas plantean la pertenencia a una comunidad con una cultura y lengua propia que se ha formado generacionalmente y que posee una serie de tradiciones que atraviesan la personalidad de los sujetos. Los procesos pedagógicos de aprendizaje basados en el constructivismo toman experiencias previas del estudiante, su entorno y su cultura para 'construir' dichos procesos. El estudiante sordo ha desarrollado plenamente aspectos importantes de pertenencia a su comunidad, lengua y cultura; significa que tales aspectos son imprescindibles y deben ser incluidos. Sin embargo, por lo general, el docente es una persona oyente, por lo que la voz del estudiante sordo, quien es -en el proceso- el sujeto con la perspectiva más clara de sus necesidades, debe ser tomada en cuenta.

También se da la identidad moral. En este caso cada individuo asume una responsabilidad moral como parte del colectivo y en relación a otros grupos sociales. Por consiguiente, una composición de las diversas identidades repercute en la llamada identidad personal, donde el sujeto se define como ser humano igual y distinto a los otros y, según Storch (2005), esta es innata y se mantiene en el tiempo. En tal sentido, la identidad permite reconocerse a sí mismo, y ser reconocido por otros como miembro de una comunidad, desarrollándose el sentido de pertenencia al grupo y la solidaridad entre los miembros, buscando el fortalecimiento, desarrollo y permanencia de su cultura.

Ahora bien, la educación de las personas sordas se ha caracterizado por ser una educación normalizadora donde todos están obligados en cierta medida a encajar dentro de los parámetros impuestos por las élites mediante políticas de subjetivación, llenas de silenciamientos, bajo una relación opresora con diálogos unidireccionales y lo que se ha denominado “colonialismo epistemológico", que según Morales y Pérez (20I0) implica la desigualdad en el reconocimiento lingüístico y cultural, considerando a la persona sorda un ser con una patología que se busca curar, lo que lleva a inscribir dichas prácticas en las instituciones educativas, negando la importancia y el acceso a su lengua y su cultura. Es decir, una dependencia epistémica que reproduce prácticas no superadas de la independencia.

En consecuencia, como se puede esperar, esta educación segregadora llevó a ver a las personas sordas desde una mirada reduccionista que implicó centrarse en la deficiencia. En la actualidad, las diferentes movilizaciones que ha hecho la comunidad sorda hacen que se posicionen desde la diferencia, comenzando a dejar atrás la deficiencia, y se ha dado una tendencia que encamina a entender a las personas sordas no desde el paradigma médicoasistencialista sino desde una perspectiva socioantropológica de la sordera, es decir, 
considerar al colectivo sordo como miembro de una minoría étnico-lingüística. Sin embargo, la educación, a pesar de llamarse inclusiva y respetar la diversidad, aún no ha alcanzado su fin: lograr la socialización e inclusión real a la sociedad y la emancipación verdadera del sujeto.

Por otro lado, considerando la educación inclusiva bilingüe-bicultural de las personas sordas, se evidencia que aún persisten algunas prácticas hegemónicas del oyente, donde la identidad de la persona y del colectivo sordo aún no tiene cabida, ya que se siguen reproduciendo patrones, "reconstruyendo constantemente el mundo al que estamos acostumbrados con el fin de mantener las regularidades y las rutinas" (Rudduck y Flutter, 2007: I32), por lo que se propone centrarse en las perspectivas de los alumnos y darles voz.

Así bien, dado que la educación de las personas sordas ha sido definida e impuesta por los oyentes, prevalecen en ella inconsistencias entre lo que se teoriza y lo que se practica y aquellos matices que implican la diversidad de ambas visiones, aspiraciones y perspectivas de los actores. Así, existen diversos vacíos y conflictos de intereses, que solo se han ido superando paulatinamente en la medida que las propias personas sordas se apropian del problema, y generan tensiones en torno a su educación asumiendo posturas como sujetos políticos y epistemológicos.

Los procesos evaluativos unilaterales, donde el docente es el único que participa en los diseños, levantan muros inexpugnables entre la opinión de los estudiantes y su posibilidad de desarrollar un amplio criterio. La unilateralidad del proceso es opuesto al propósito de la educación. Un claro ejemplo es la planificación de evaluaciones escritas. Los estudiantes oyentes realizan evaluaciones escritas en su lengua materna, las personas sordas las hacen en una segunda lengua al enfrentarse a la lengua escrita. Más que evaluar los aprendizajes del estudiante en el caso específico del contenido, se evalúa su capacidad de expresar tales conocimientos en una segunda lengua, dejando atrás la equiparación de oportunidades. En tal situación ¿cuál sería la opinión del estudiante sordo? Desde su cosmovisión ¿cuál sería el proceso evaluativo justo de acuerdo a sus necesidades? Al darle valor a su voz desde los procesos evaluativos, se puede generar un pensamiento crítico y reflexivo que le permita juzgar su participación en la sociedad y lograr el empoderamiento necesario para argumentar las transformaciones sociales esperadas.

En este sentido, se requieren instituciones educativas que propicien la reflexión crítica mediante la co-construcción por parte de los actores, lo cual lleva a generar intereses colectivos y a definir una responsabilidad compartida (Rudduck y Flutter, 2007). Por ello, se hace necesaria una evaluación democrática, donde se reconozca realmente la subjetividad e identidad de la persona sorda, y se abran espacios de participación bidireccional, para alcanzar el ejercicio efectivo de la ciudadanía logrando un despliegue de saberes-poderes.

La educación inclusiva implica una educación para y desde todos, donde se aprovecha la diversidad y heterogeneidad del aula, reconociendo así tanto el derecho a la educación como el derecho a la identidad personal y a la identidad y sentido de pertenencia a grupos. Esta educación surge como un nuevo paradigma, dejando atrás los procesos de “integración”. Esta última se centraba en superar las debilidades de la persona de manera individualizada, fuera del aula, esperando un cambio en el sujeto con el fin de que se adaptara a los parámetros. Mientras que la educación "inclusiva" se centra en las fortalezas de las personas y cómo con estas se pueden superar las debilidades, con apoyo dentro del aula -en igualdad de condiciones con los otros- y aprovechando la diversidad con el fin de que los cambios no vengan del individuo sino que la escuela y sus miembros realicen cambios, en especial de actitud, para lograr ofrecer un proceso de enseñanza que garantice la igualdad en la educación para todos.

Así la inclusión, en el caso de las personas sordas, debe apostar por lograr el bilingüismo y el biculturalismo, rompiendo con los 
patrones oyentes impuestos y garantizando las especificaciones lingüísticas, culturales, cognitivas y sociales propias de las personas sordas en las aulas. Es decir, aulas que evidencien un compromiso por parte de todos los miembros de la comunidad educativa, defendiendo no solo el derecho a la educación, sino un enfoque de derechos, amplio abarcando derechos culturales, lingüísticos, sociales, identitarios y participativos.

Lucas y Schatz $(2003)$ sostienen que debido a que solo un Io\% de los niños sordos nacen de padres sordos, se entiende que en su mayoría estos se enfrentan a un contexto propio de los oyentes. Por este motivo, es en el grupo de pares donde se logra el despliegue de su lengua, cultura e identidad, y dicho grupo pasa a tener un rol primordial en la vida del sujeto, incluso en mayor grado que el de su familia.

Frente a lo dado, se requiere actuar desde otro modo y continuar la transformación en la educación de las personas sordas. Así, la participación en el proceso de evaluación despliega una forma de accionar distinta, como se ha expuesto, permitiendo el reconocimiento de sus intereses e identidad, dando protagonismo al sujeto y participación activa a sus pares. La barrera lingüística ya no es excusa para que el maestro argumente deficiencias en la conciencia del estudiante sordo, eso quedó afortunadamente en el pasado. Se ha ganado un vasto terreno al lograr el reconocimiento y respeto de la lengua de signos, en especial para el auto-reconocimiento de comunidades ya existentes que solían permanecer en silencio. Sin embargo, hay considerables campos que abordar todavía. Se logró el reconocimiento de la lengua de signos, pero falta abrir espacios donde se le permita ser fructífera para y desde el núcleo mismo de su razón de ser: sus hablantes.

En una actualidad donde la información no está oculta por barreras de espacio o tiempo, los estudiantes tienen a su alcance infinidad de herramientas que pueden ser de gran utilidad en el aula. "Hay un desfase entre los saberes que se producen en la escuela y los que se requieren en un mundo competitivo, globalizado y cada vez más fragmentado" (Morales, 20IO: I). Dar participación a los estudiantes es romper las barreras de un tradicionalismo absurdo sin cabida en el mundo moderno, es abordar los requerimientos del exterior y transformarlos en competencias de liderazgo. Este nuevo siglo se caracteriza por la abundancia de opiniones y la necesidad de consensuarlas de manera positiva. Los procesos evaluativos no escapan de tal necesidad.

Al respecto, Ibarra, Rodríguez y Gómez (20I 2) proponen la evaluación entre iguales que, por las particularidades antes descritas de la comunidad sorda, eleva los niveles de satisfacción y mejora los procesos y productos en relación al aprendizaje y las habilidades sociales, facilitando la inclusión y la construcción de su identidad. La mediación con los pares aumenta la motivación en los estudiantes, lo cual se traduce en mayor participación y protagonismo en los procesos de evaluación, promoviendo aprendizajes significativos.

Así, el hecho de que en la comunidad sorda la influencia de sus pares sea tan determinante lleva a re-pensar sobre qué acciones se pueden llevar a cabo en las políticas e instituciones educativas para sacarle provecho. En las instituciones educativas se hace necesario promover el protagonismo de las personas sordas como directivos, docentes y estudiantes, debido a su gran impacto en el proceso de enseñanza-aprendizaje. En la medida en que las nuevas generaciones se vean reflejadas en líderes mayores, quienes son miembros de su misma comunidad, las relaciones se fortalecerán y las acciones se afianzarán.

Recogiendo lo expuesto, para lograr alcanzar el poder performativo de la educación, mediante la evaluación, se puede comenzar con el reconocimiento del otro como igualmente diferente, como sujeto epistémico, en igualdad de derechos, tratamiento y condiciones, y no objetivizarlo, trabajando a favor de una evaluación democrática centrada en la reflexión crítica. Por consiguiente, se hace necesaria la generación de continuos cuestionamientos, donde se evidencie un proceso con pluralidad 
en los análisis, comprendiendo las capacidades de reflexión y de comunicación de los actores, respetando sus valores socioculturales, prioridades, vulnerabilidades e inquietudes; permitiendo y promoviendo la capacidad dialógica, deliberativa, comunicativa, interpretativa, pensando en el contexto y las particularidades de la comunidad sorda e involucrándola en su proceso evaluativo.

Por ello, existe la necesidad de que esta evaluación se centre en propuestas coherentes, efectivas y ajustadas a la comunidad y esto es posible de alcanzar dándoles la voz a los mismos estudiantes sordos, y compartiendo la toma de decisiones entre el sujeto, su grupo de pares y la comunidad de oyentes. Esto requiere un replanteamiento de la escuela y de la educación de las personas sordas, pensando en su visibilización, participación y empoderamiento en los procesos educativos, en particular en la evaluación, ya que es donde se desarrolla y afianza la capacidad de toma de decisiones y se establecen juicios.

A pesar de que Brown y Glasner presentan la importancia que tiene a nivel universitario la evaluación por los compañeros, exponiendo que fortalece las prácticas profesionales y tiene implicaciones pedagógicas, en la medida que el desarrollo de "una identidad profesional se genera mejor en un contexto compartido común” (Brown y Glasner, I999: I 56), dicha afirmación se presta a consideraciones más amplias. Ciertamente la evaluación por compañeros posee una gran importancia desde temprana edad, donde el niño en sus primeros acercamientos a la escuela puede comenzar a generar ese contexto compartido sintiéndose reflejado en los otros, desarrollando su sentido de pertenencia a grupos y adquiriendo desde pequeño una identidad común, que luego se traducirá en aspectos más amplios como puede ser, entre otros, la identidad profesional.

En consecuencia, construyendo una comunidad educativa inclusiva desde la educación inicial y a lo largo de todos los niveles educativos, considerando los espacios, lugares y lenguajes, se pueden transformar los significados de la escuela mediante renovaciones en los intereses, ideales, percepciones y prácticas. Se rompe con el individualismo, se comienza a trabajar de manera colectiva respondiendo a intereses propios y grupales y dando-aceptando juicios valorativos de manera justa y constructiva. Para ello, resulta indispensable cuestionar lo obvio, cuestionar las prácticas admitidas y luego -a partir de los saberes propios de la comunidad- lograr una evaluación democrática con miras a alcanzar un poder transformador. 


\section{Referencias bibliográficas}

Brown, S. y Glasner, A. (I999): Evaluar en la universidad. Problemas y nuevos enfoques, Madrid: Narcea S.A.

Freire, P. (2005): Pedagogía del oprimido. "La dialogicidad: Esencia de la educación como práctica de la libertad”, México: Siglo XXI.

Ibarra, M. y Rodríguez, G. et al. (20I2): "La evaluación entre iguales: beneficios y estrategias para su práctica en la universidad", Revista de educación, 359: I-I9.

Lucas, C. y Schatz, S. (2003): "Sociolinguistic dynamics in american deaf communities: Peer groups versus families" En: Monaghan, L. (ed.): Many ways to be deaf: International variation in deaf communities, Washington, D.C: Gallaudet University Press: I4I-I 52.

Morales, A. (2010): Apuntes para repensar la educación desde la diferencia (en línea). <http://www.cultura-sorda.eu/resources/ Morales_apuntes_para_repensar_educacion_ desde-la_diferencia_2oro.pdf $>$, acceso I 5 de noviembre del 2013 .

Morales, A. y Pérez, Y. (2005): La educación del sordo en Venezuela: Una visión crítica (en línea). <http://www.cultura-sorda.eu/resources/ Morales-y-Perez-La_educacion_del_sordo_ Venezuela_20Io.pdf $>$, acceso Io de enero del 2012.

Rudduck, J. y Flutter, J. (2007): Como mejorar tu centro escolar dándole la voz al estudiante, Madrid: Morata.

Storch, J. (2005): Comunidad, identidad y derechos humanos lingüísticos: Una visión desde la filosofía del lenguaje, Comunicación al II Congreso Nacional de Lengua de Signos Española, Universidad de Valladolid. 